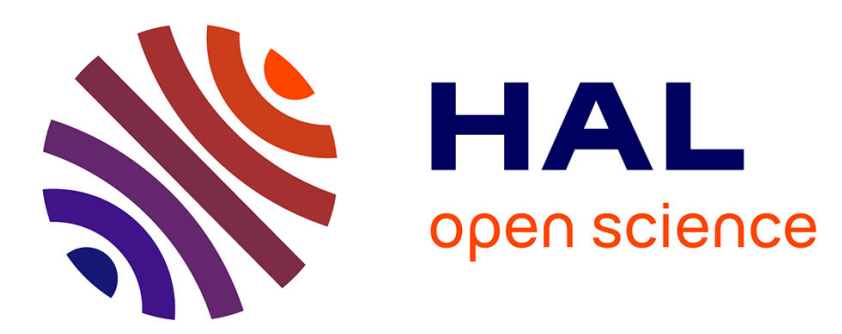

\title{
Using Low-Frequency Earthquake Families on the San Andreas Fault as Deep Creepmeters
}

\author{
A. Thomas, N. Beeler, Quentin Bletery, R. Bürgmann, D. Shelly
}

\section{To cite this version:}

A. Thomas, N. Beeler, Quentin Bletery, R. Bürgmann, D. Shelly. Using Low-Frequency Earthquake Families on the San Andreas Fault as Deep Creepmeters. Journal of Geophysical Research: Solid Earth, 2018, 123 (1), pp.457-475. 10.1002/2017jb014404 . hal-02383079

\section{HAL Id: hal-02383079 \\ https://hal.science/hal-02383079}

Submitted on 3 Sep 2021

HAL is a multi-disciplinary open access archive for the deposit and dissemination of scientific research documents, whether they are published or not. The documents may come from teaching and research institutions in France or abroad, or from public or private research centers.
L'archive ouverte pluridisciplinaire HAL, est destinée au dépôt et à la diffusion de documents scientifiques de niveau recherche, publiés ou non, émanant des établissements d'enseignement et de recherche français ou étrangers, des laboratoires publics ou privés.

$$
\text { Copyright }
$$




\section{Journal of Geophysical Research: Solid Earth}

\section{RESEARCH ARTICLE \\ 10.1002/2017JB014404 \\ Special Section: \\ Using Low-Frequency Earthquake Families on the San Andreas Fault as Deep Creepmeters}

Slow Slip Phenomena and

Plate Boundary Processes

Key Points:

-We define slip episodes, or clusters of individual LFE occurrence, based on properties of LFE recurrence intervals -We formalize the definition of a creepmeter and determine its applicability to LFE families on the deep San Andreas Fault

-We find that episodic families meter creep and reflect surrounding SSEs, while continuous families reflect asperities that fail in response to continuous creep

Correspondence to:

A. M. Thomas,

amt.seismo@gmail.com

Citation:

Thomas, A. M., Beeler, N. M., Bletery, Q., Burgmann, R., \& Shelly, D. R. (2018). Using low-frequency earthquake families on the San Andreas Fault as deep creepmeters. Journal of Geophysical Research:

Solid Earth, 123, 457-475.

https://doi.org/10.1002/2017JB014404

Received 3 MAY 2017

Accepted 14 SEP 2017

Accepted article online 22 SEP 2017

Published online 22 JAN 2018

O2017. American Geophysical Union. All Rights Reserved.

\author{
A. M. Thomas ${ }^{1}$ (D) , N. M. Beeler ${ }^{2}$, Q. Bletery ${ }^{1}$ iD, R. Burgmann ${ }^{3}$ D, and D. R. Shelly 4 \\ ${ }^{1}$ Department of Geological Sciences, University of Oregon, Eugene, OR, USA, ${ }^{2}$ U.S. Geological Survey, Vancouver, WA, USA, \\ ${ }^{3}$ University of California, Berkeley, CA, USA, ${ }^{4}$ U.S. Geological Survey, Menlo Park, CA, USA
}

\begin{abstract}
The central section of the San Andreas Fault hosts tectonic tremor and low-frequency earthquakes (LFEs) similar to subduction zone environments. LFEs are often interpreted as persistent regions that repeatedly fail during the aseismic shear of the surrounding fault allowing them to be used as creepmeters. We test this idea by using the recurrence intervals of individual LFEs within LFE families to estimate the timing, duration, recurrence interval, slip, and slip rate associated with inferred slow slip events. We formalize the definition of a creepmeter and determine whether this definition is consistent with our observations. We find that episodic families reflect surrounding creep over the interevent time, while the continuous families and the short time scale bursts that occur as part of the episodic families do not. However, when these families are evaluated on time scales longer than the interevent time these events can also be used to meter slip. A straightforward interpretation of episodic families is that they define sections of the fault where slip is distinctly episodic in well-defined slow slip events that slip 16 times the long-term rate. In contrast, the frequent short-term bursts of the continuous and short time scale episodic families likely do not represent individual creep events but rather are persistent asperities that are driven to failure by quasi-continuous creep on the surrounding fault. Finally, we find that the moment-duration scaling of our inferred creep events are inconsistent with the proposed linear moment-duration scaling. However, caution must be exercised when attempting to determine scaling with incomplete knowledge of scale.
\end{abstract}

\section{Introduction}

While many slow slip events (SSEs) are aseismic and can only be detected using geodetic techniques, some slow earthquakes do have a seismic manifestation. For example, long-duration, small-amplitude seismic signals, dubbed nonvolcanic tremor (NVT) or tectonic tremor, usually lack the obvious impulsive phase arrivals associated with regular earthquakes and are depleted in high-frequency content relative to conventional earthquakes of the same moment (Ide et al., 2007; Obara, 2002). Short-duration seismic signals known as low-frequency earthquakes (LFEs) more closely resemble conventional earthquakes and were initially found to occur as part of tremor episodes (Shelly et al., 2007). Shelly et al. (2007) demonstrated that the NVT signal in Japan can be explained as a superposition of many LFEs. Similar analysis was later applied to tremor on the Parkfield section of the San Andreas Fault (SAF), which has produced a catalog of over one million LFEs detected between 2001 and 2016 grouped into 88 different families based on waveform similarity between events (Shelly, 2017). Locations and depths of these 88 LFE families are shown in Figure 1.

Within individual LFE families event occurrence is not steady. In some families, groups of a few events recur on time scales of days, while in other families there are nearly quiescent periods that often last for months followed by the occurrence of hundreds of events over the course of a few days (Shelly \& Johnson, 2011; Thomas et al., 2012). These two end-member behaviors are shown in Figures $2 \mathrm{a}$ and $2 \mathrm{~b}$ and are termed continuous and episodic, respectively. These styles of occurrence are not unique to Parkfield (Chamberlain et al., 2014; Frank et al., 2015; Royer et al., 2015; Wech \& Creager, 2011). Though there is no geodetic signal associated with times of high LFE rate on the SAF (Smith \& Gomberg, 2009), the cycle of quiescence followed by high-seismicity rate in the most episodic families is reminiscent of tremor accompanying SSEs in subduction zones. Shelly and Johnson (2011) quantified the episodicity of 88 LFE families on the deep SAF by measuring the minimum fraction of days necessary to contain 75\% of all events (abbreviated MFD75). MFD75 scales inversely with family episodicity so that continuous families (Figure 2a) have high MFD75, while episodic 


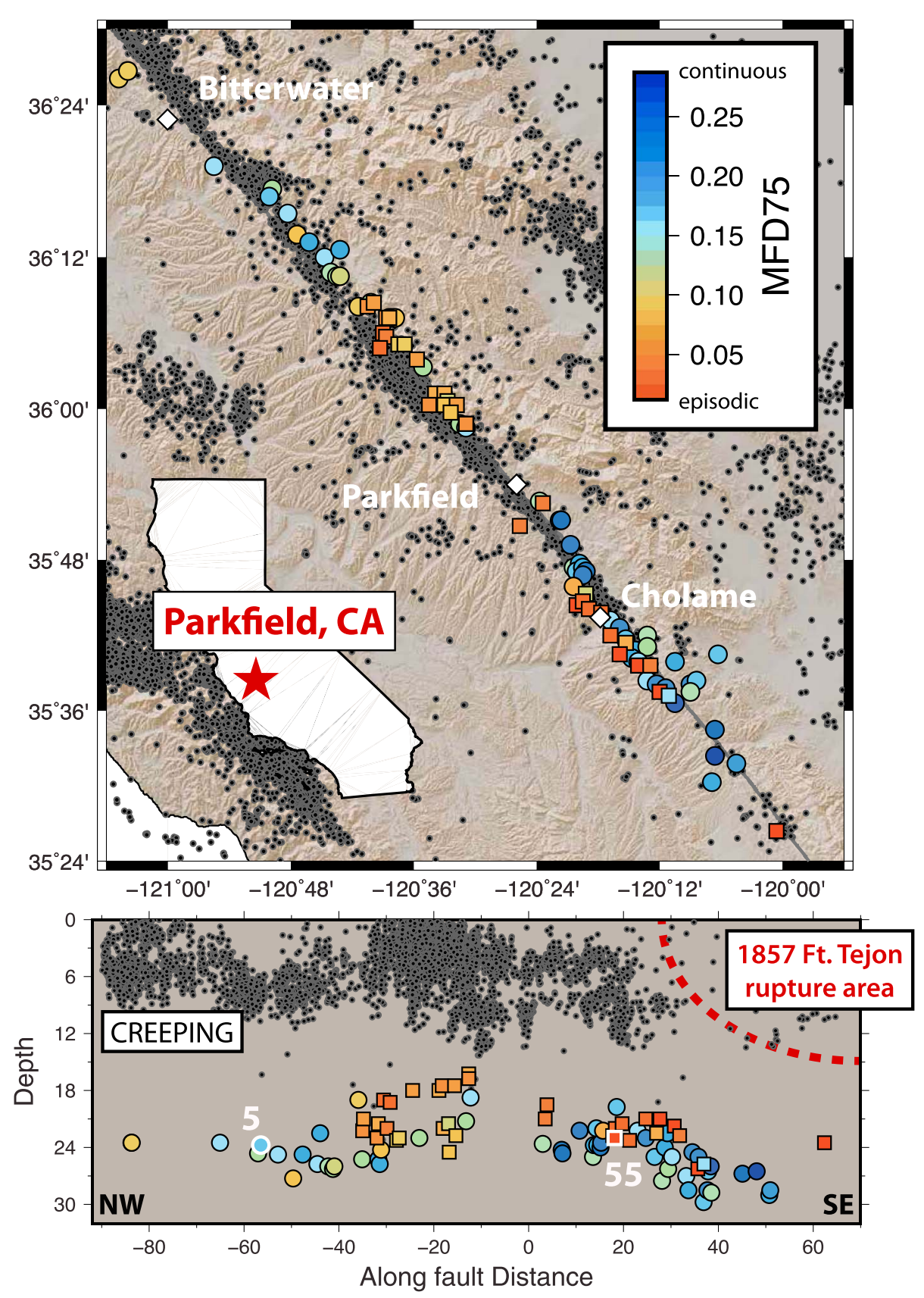

Figure 1. (top) Parkfield area location map with LFE locations are plotted as either circles (continuous families) or squares (episodic families) and color coded by MFD75 which is the minimum fraction of days required to contain $75 \%$ of the events in each family (Shelly \& Johnson, 2011). Hypocenters of earthquakes that occurred in the last decade (i.e., 2006-2016) are shown as gray dots. Inset shows location of Parkfield within the state of California. (bottom) Along fault cross section of the San Andreas viewed from the southwest (vertically exaggerated 2 times) showing locations of LFE families shown in the top and earthquakes within $10 \mathrm{~km}$ of the fault. The creeping and locked sections of the fault are annotated with approximate location of the 1857 Fort Tejon rupture area indicated by the dashed red line.

families (Figure 2b) have low MFD75. MFD75 values for the 88 LFE families in Parkfield are shown in Figure 1. Shelly and Johnson (2011) also note a first-order decrease of episodicity with depth. Similar changes in episodicity with depth have been observed using tremor in Cascadia (Wech \& Creager, 2011) and low-frequency earthquakes in Japan (Obara, 2010) and Cascadia (Royer et al., 2015). Additionally, some LFE families have slip histories that closely resemble those of neighboring families suggesting that these distinct LFE families take part in the same underlying slip episode (Shelly, 2015; Trugman et al., 2015). 

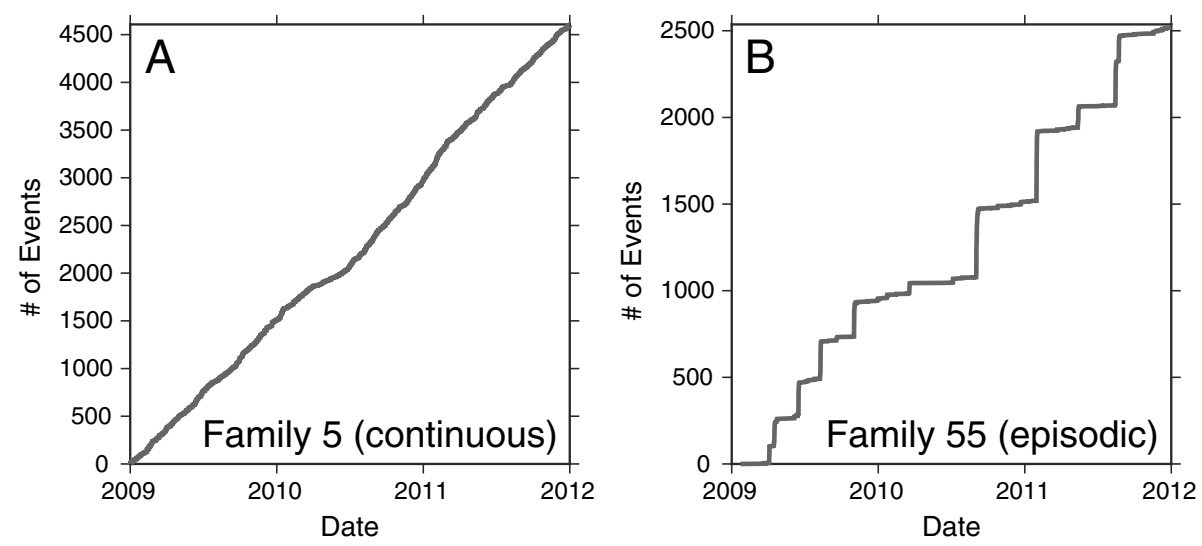

Figure 2. (a) The cumulative number of LFEs in family 5 , a continuous family, as a function of time for the 3 year period from 2009 to 2012. (b) The same as Figure 2a but for episodic family 55. Locations of both families are shown in Figure 1.

One simple, popular conceptual model for LFEs is that like shallow repeating earthquakes, they represent radiation emanating from small, persistent regions that repeatedly fail during the aseismic shear of the larger-scale surrounding fault zone (Bufe et al., 1977; Schaff et al., 1998; Shelly et al., 2007; Nadeau \& McEvilly, 1999). In this model, the earthquakes source itself is sufficiently small and its occurrence is a passive meter of the rate of fault creep. If this model is valid then the seismicity rate $R$ is proportional to the slip rate $V$ on the surrounding fault

$$
R=V / d
$$

Here $d$ is the characteristic slip per event. Equation (1) has the added implication that

$$
V / V_{L}=R / R_{L}
$$

$R_{L}$ is the seismicity rate at a reference creep rate $V_{L}$. Equation (2) quantifies the relationship between the seismicity rate and the slip rate of the fault, and its application potentially allows each LFE source to be used as a fault creepmeter that could be monitored in near real time due to the large number of LFEs per family (Table 1) and the short interevent times.

Accelerated deep slip is thought to have preceded a number of recent large subduction zone earthquakes, and repeating earthquake occurrence well documents both short-term and very long term precursory slip (Kato \& Nakagawa, 2014; Kato et al., 2012; Mavrommatis et al., 2015; Meng et al., 2015; Ruiz et al., 2014; Uchida et al., 2016). Accordingly, there is interest in monitoring deep plate motions worldwide for slip transients. The Parkfield section of the SAF is an ideal location to explore the use of LFEs as deep creepmeters for several reasons. First, LFE families in Parkfield extend beneath the probable nucleation zone of the last great San Andreas earthquake in Southern California, the 1857 M7.9 Fort Tejon earthquake (Sieh, 1978) (Figure 1). The proximity of LFEs to this hazardous earthquake source motivates using them for near real-time monitoring of fault slip. Additionally, there is evidence that the last $M 6$ at Parkfield may have been preceded by accelerated deep slow slip (Shelly, 2009). Second, events in each LFE family in central California occur on average a few times per day which is advantageous because monitoring of the slip rate would be possible on daily or weekly basis and accelerated slip rates could be resolved on much shorter time scales. Third, the LFE catalog in Parkfield contains nearly one million earthquakes recorded since 2001. This amount of data allows for robust characterization of what "normal" behavior is, potentially allowing for detections of precursory transients that are abnormal.

Despite the simplicity of the idea and implementation of equation (2), in practice relating LFE rates to fault slip rate may not be so straightforward. LFE family cross-correlation detections are implemented using a forgiving correlation coefficient, typically as low as 0.16 (Shelly, 2017). How this loose definition of a family relates to a slip patch and whether family seismicity rates can be used without modification with the conceptual model in equation (2), remains to be seen. Additionally, equation (2) assumes that no aseismic slip occurs on the LFE patches whereas modeling studies have found that repeating earthquake asperities may accommodate a 


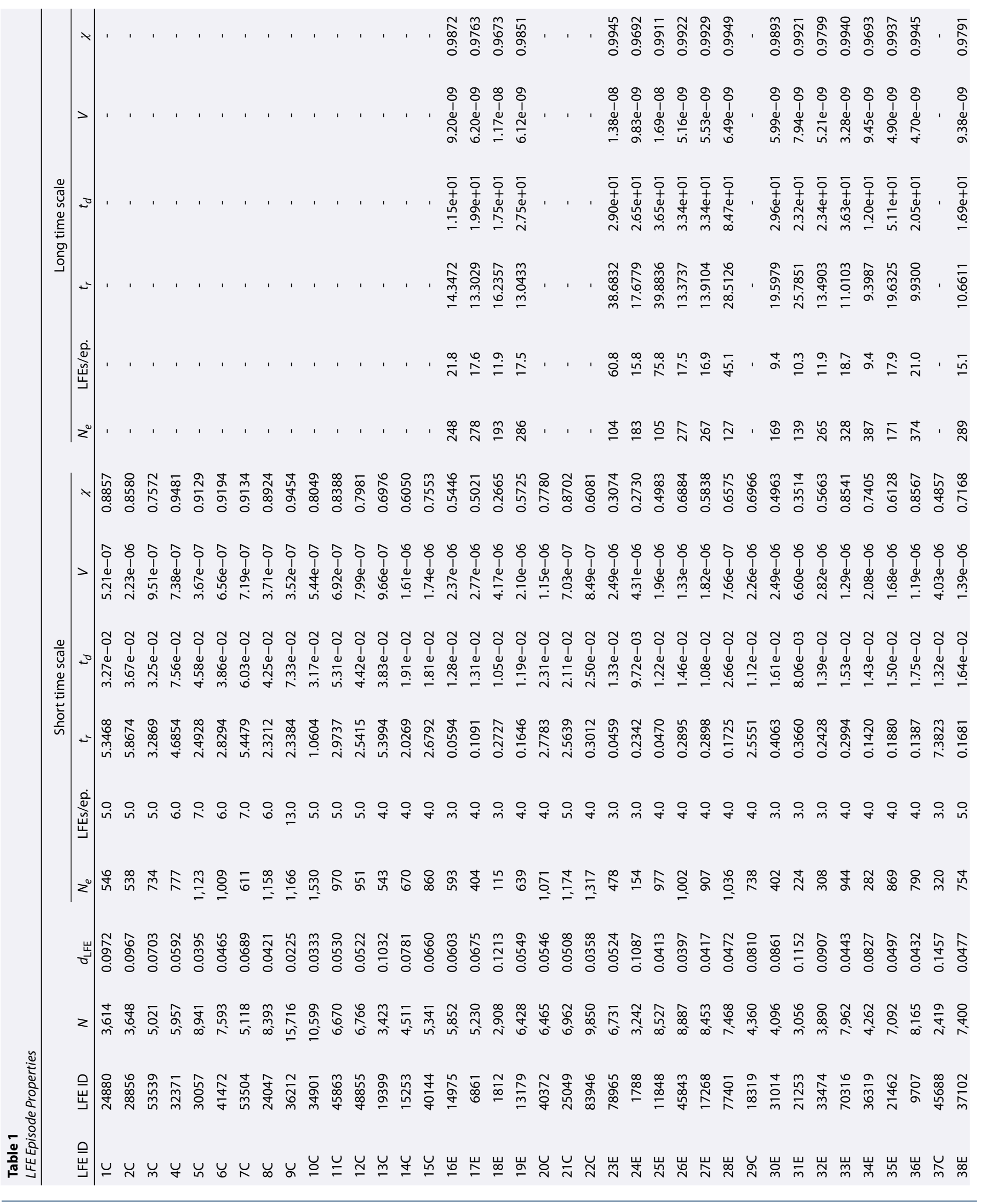




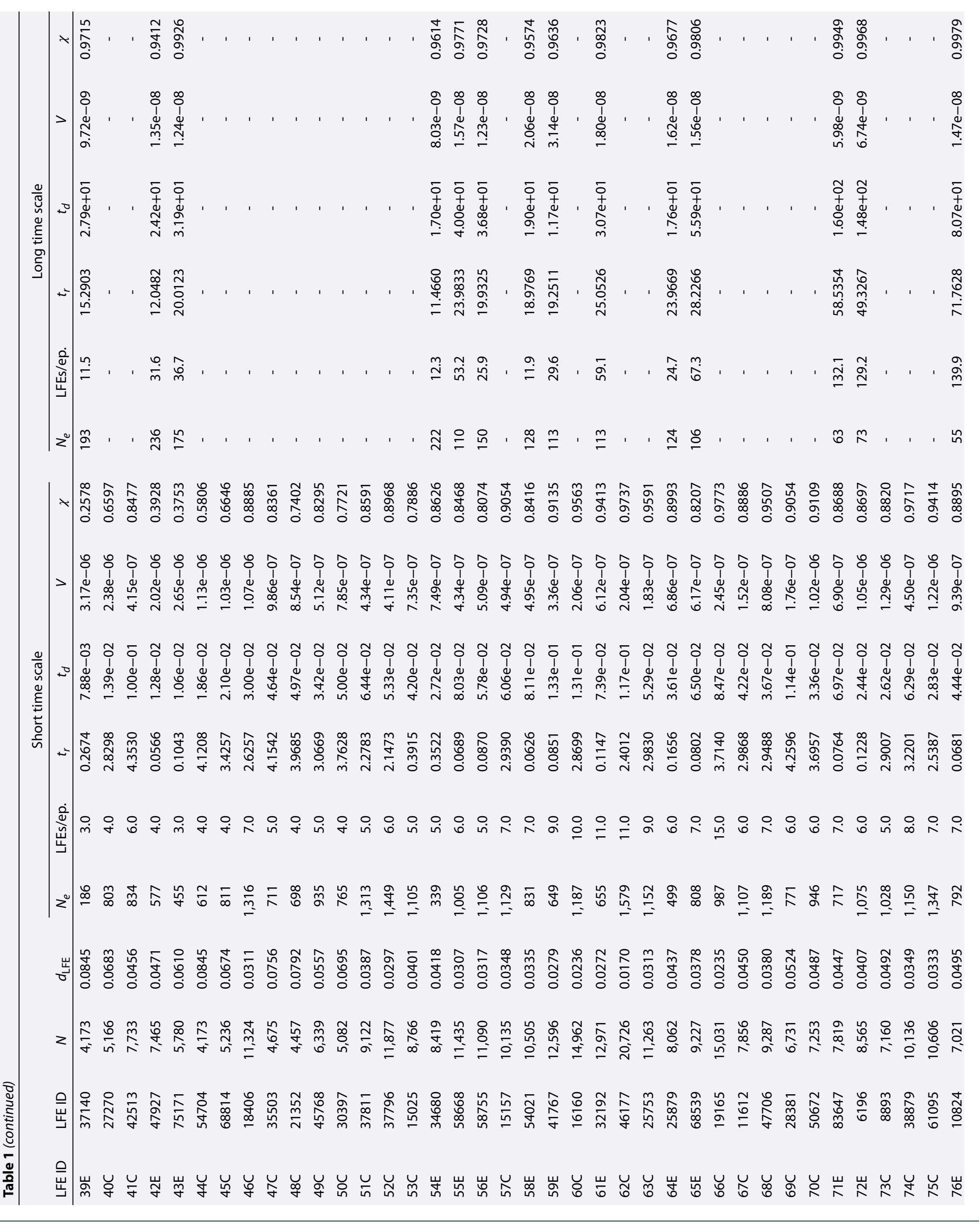




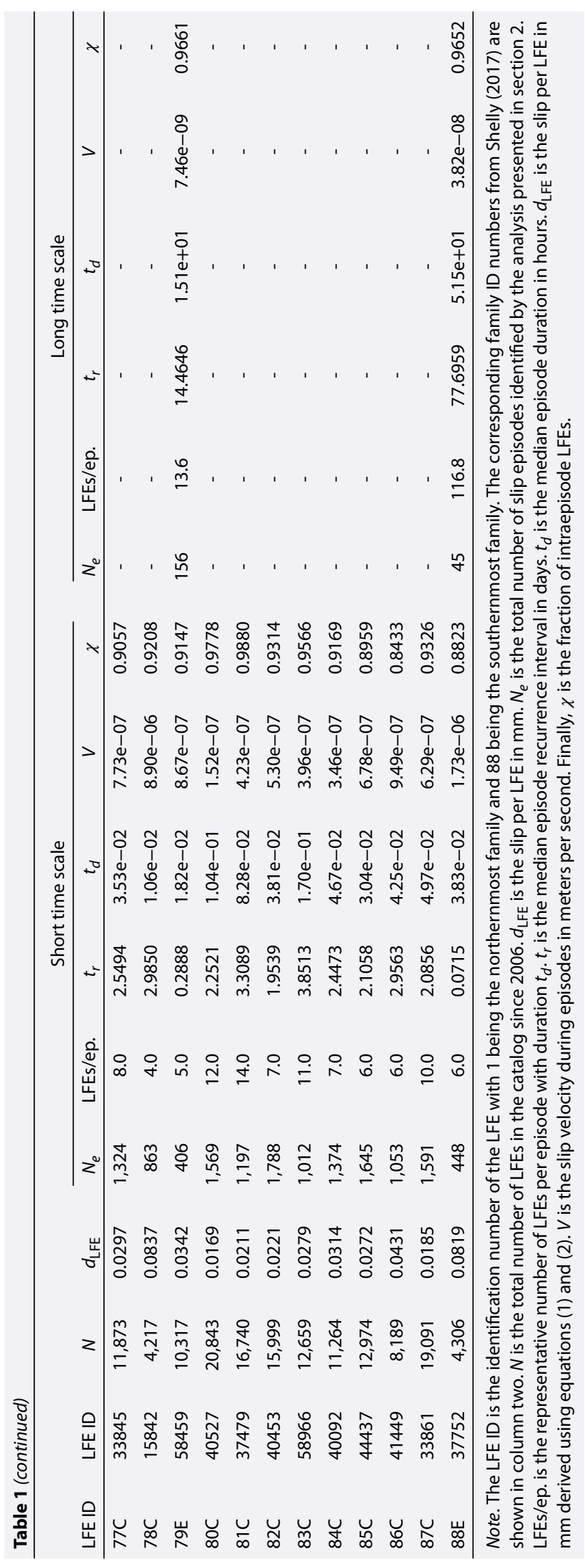


significant amount of aseismic slip (Chen \& Lapusta, 2009). Finally, the seismicity rate, $R$, in equation (2) must be evaluated over some user defined time scale, and it is unclear which time scale is most appropriate.

Here we attempt to determine whether the occurrence of LFEs on the deep SAF provide a direct measure of the distribution of creep at depth and over what time scale. We do this by processing a catalog of 88 LFE families to determine average properties of periods of accelerated LFE occurrence and the SSEs they are through to reflect. Throughout the manuscript we use the terms SSE and creep episode interchangeably. Using the occurrence time and location of each LFE family, we estimate the average recurrence interval and duration of episodes. We then assume that equations (1) and (2) are valid and use the estimates of slip that can be derived from those assumptions to estimate additional properties such as the average total slip per episode, slip rate, fraction of interepisode LFEs, and relative episode moment. Finally, we explore the implications of these assumptions and determine whether they are physically realistic.

\section{Methods}

The data used in our analysis are the 88 LFE families identified by Shelly (2017). The catalog includes over one million earthquakes recorded since 2001; however, we limit our analysis to between 2006 and May of 2016 to minimize the effect of afterslip from the 2004 M6 Parkfield earthquake. LFE detections are identified by taking template waveforms recorded on many stations and channels and cross correlating them with continuous seismic data. The time series of cross correlations for each template are then summed over each station and channel to create a network cross-correlation time series. An LFE detection is registered when this network cross correlation exceeds a given threshold. Many studies use 8 times the median absolute deviation; however, Shelly (2017) instead required that the average cross correlation across all channels was 0.16 or greater and that the summed cross-correlations values exceeded 4.0. So defined, an LFE family represents events with similar waveforms, ensuring that they have similar mechanisms and similar source locations. However, it is uncertain whether these events are exact repeats of the same source at the same spot on the fault as nearby, as distinct sources can generate waveforms similar enough to meet the LFE detection criterion. Additionally, estimated LFE source dimensions of hundreds of meters (e.g., Bostock et al., 2015; Thomas et al., 2016) are typically less than LFE location uncertainties of $1-2 \mathrm{~km}$ (Shelly, 2017). Because of these uncertainties we apply equation (2) to slip episodes or periods in time when LFEs within a given family occur in rapid succession, as opposed to individual LFEs.

To define duration of slip episodes on the deep SAF, we take the distribution of recurrence intervals $T_{r}$, or the time between an LFE and its previous occurrence, for each individual LFE family and plot the logarithm of $T_{r}$ as a function of time (see Figures $3 a$ and $4 a$ ). For all LFE families, there is a clear separation into two or sometimes three populations of interevent times. To determine the time scale that separates populations, we first plot the smoothed histogram of the logarithm of recurrence intervals (for step sizes of 0.1 and a bin of width of 0.6 , measured in log (days)). These histograms are shown in Figures $3 \mathrm{~b}$ and $4 \mathrm{~b}$ and have clear peaks corresponding to the different event populations. We then find the local minima in this distribution while requiring a minimum separation distance of 1 order of magnitude between successive minima. While these values are arbitrary, we find that they result in time scales that are consistent with identifying populations by eye. An example of continuous family 5 with two populations is shown in Figure 3a. We use the time scale corresponding to the minimum LFE frequency (vertical red line in Figure $3 \mathrm{~b}$ ) to assign each LFE to a $\log \left(T_{r}\right)$ population. In this case, and in most continuous families, the long recurrence interval population is interpreted to represent the first event in each episode, while the short recurrence interval populations are thought to represent LFEs that occur as part of an ongoing episode. This interpretation is consistent with observations of clustering behavior of LFEs in time. For example, Figure 3c shows the cumulative number of LFEs in family 5 versus time for a 1 week period in 2012 with the LFE symbol corresponding to its $\log \left(T_{r}\right)$ population. Family 5 has episodes that tend to occur frequently (i.e., approximately every 3 days, see Table 1), and each episode begins with an event in the long $\log \left(T_{r}\right)$ population and often has several short $\log \left(T_{r}\right)$ events that follow. In episodic families, such as family 55 , there are three $\log \left(T_{r}\right)$ populations (Figures $4 \mathrm{a}$ and $4 \mathrm{~b}$ ). The episode shown in Figure 4c initiates with a long $\log \left(T_{r}\right)$ event, in this case any LFE with recurrence interval greater than 1.5 days, and includes multiple groups of LFEs consisting of an intermediate $\log \left(T_{r}\right)$ followed by multiple short $\log \left(T_{r}\right)$ events. Like the continuous families, the long $\log \left(T_{r}\right)$ populations represent LFEs that initiate episodes while the short $\log \left(T_{r}\right)$ LFEs occur as part of an ongoing episode. The intermediate population reflects LFEs that initiate short-duration episodes, or "bursts," that occur within longer duration episodes. These bursts are 

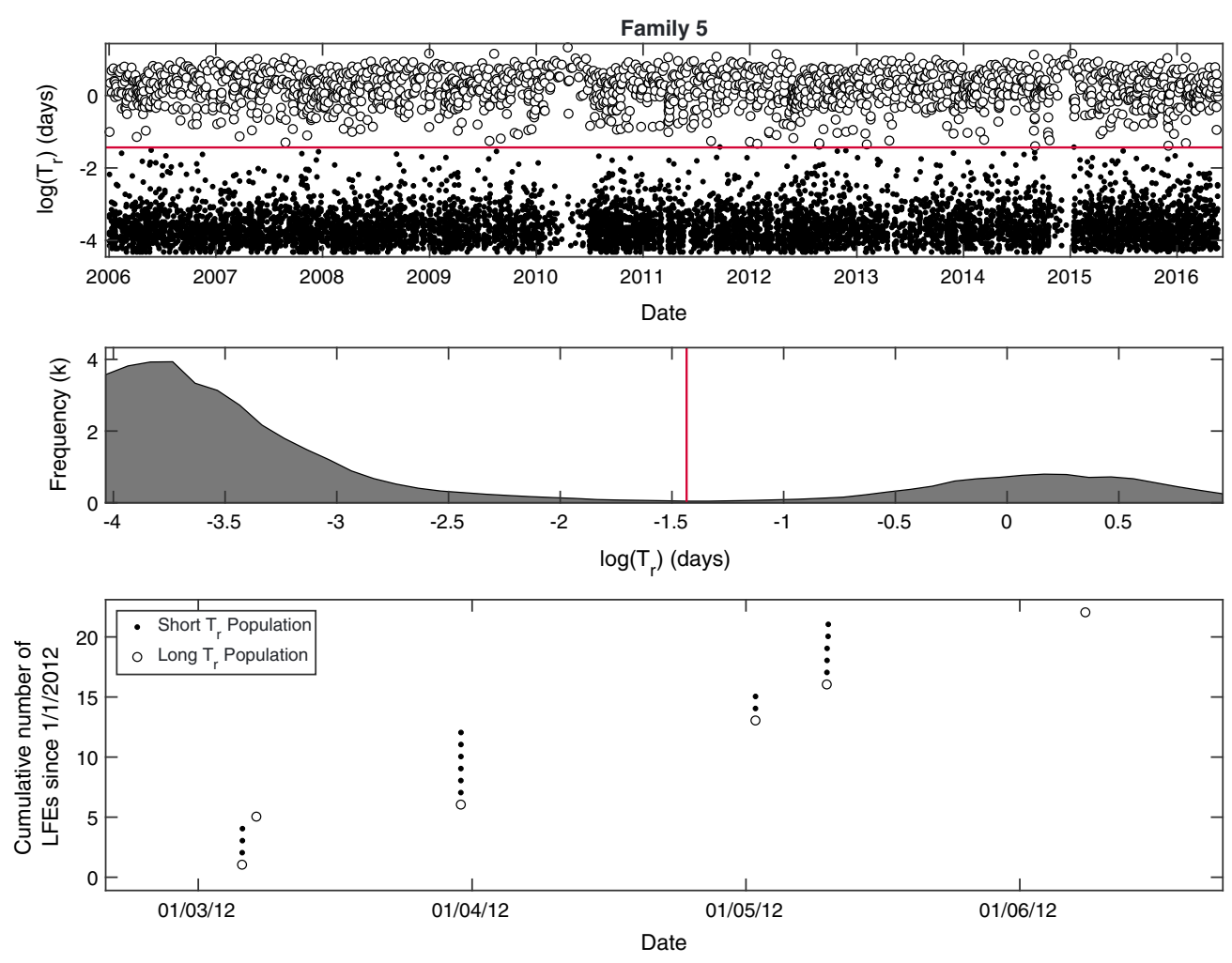

Figure 3. (a) Date versus $\log \left(T_{r}\right)$ for continuous family 5 . Red horizontal lines mark boundaries between recurrence interval populations. (b) Smoothed histogram of $\log \left(T_{r}\right)$. Local minima are marked by vertical red lines. The $\log \left(T_{r}\right)$ values are used to separate each individual LFE in family 5 into populations of events with similar preceding recurrence intervals. (c) Cumulative number of events versus time plot for family 5 for 4 days in 2012. Each individual LFE occurrence is indicated by the symbol corresponding to the long and short $\log \left(T_{r}\right)$ populations. Note that family 5 has episodes lasting 2.75 min every 2.49 days (though there are a total of six episodes in the 6 week period shown). The inset in Figure $3 c$ shows the definition of duration for a given episode.

reminiscent of the secondary slip fronts that have been observed in Cascadia and Japan (Houston et al., 2011; Obara et al., 2012).

We define an episode as two or more successive recurrence intervals (a minimum of three LFEs) shorter than the time scale separating the $\log \left(T_{r}\right)$ populations. Because the episodic families have two relevant time scales, for each episodic family we explore the implications of defining episodes based on both the short and long recurrence interval time scales. In the remainder of the manuscript, each episodic family is represented twice: once for episodes defined using the short time scale (short time scale episodic families) and once for episodes defined using the long time scale (long time scale episodic families). Using this definition of episodes, we can also define individual slip episodes for each family and estimate their duration, $t_{d}$, as the time between the occurrence of the first and last LFE that takes part in the episode. The episode recurrence interval, $t_{r}$, is defined as the time between successive episode start times. For the episodic families with episodes defined using the long time scale, we consider only episodes that have durations greater than the short time scale (which ensures that they contain multiple bursts) when calculating the recurrence interval and duration. Similarly, since our analysis of the episodic families using the short recurrence interval time scale is meant to better understand properties of bursts that occur as part of inferred creep episodes, we require that the burst recurrence interval be shorter than the long time scale when calculating the recurrence interval and duration. We also calculate a parameter, $\chi$, which we define as the fraction of LFEs in each family that occur during episodes. We estimate the total slip per LFE, $d_{\mathrm{LFE}}$, by taking long-term slip rate of $34 \mathrm{~mm} / \mathrm{yr}$ (Ryder \& Bürgmann, 2008), multiplying by the catalog duration to determine a total slip and dividing by the total number of LFEs in that family, $N$. When $d_{\mathrm{LFE}}$ is combined with the number of LFEs per episode, this yields an estimate of the slip per episode, $d_{e}$, and we also calculate the interepisode slip $d_{\mathrm{ie}}$. These calculations assume catalog completeness, that each LFE detection is an exact repeat and ruptures the same fault area and that 

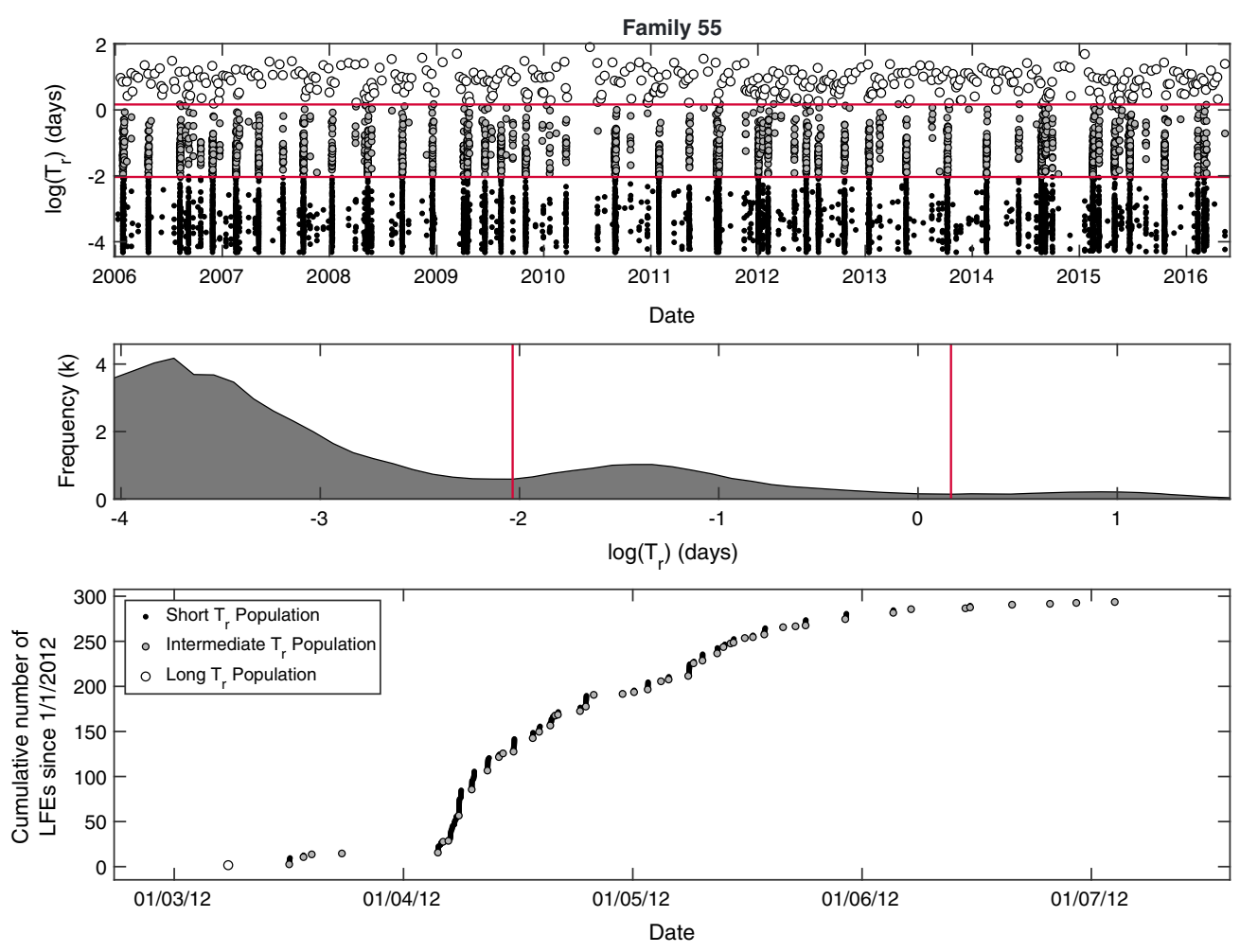

Figure 4. (a) Date versus $\log \left(T_{r}\right)$ for episodic family 55. Red horizontal lines mark boundaries between recurrence interval populations. (b) Smoothed histogram of $\log \left(T_{r}\right)$. Local minima are marked by vertical red lines. The $\log \left(T_{r}\right)$ values are used to separate each individual LFE in family 55 into populations of events with similar recurrence intervals. (c) Cumulative number of events versus time plot for family 55 for 5 days in 2012. Each individual LFE occurrence is indicated by the symbol corresponding to the long, intermediate, and short $\log \left(T_{r}\right)$ populations. Family 55 has an individual episodes that last $42 \mathrm{~h}$ every 13 days.

all slip on that fault area is accommodated seismically. Finally, dividing the slip per episode by the episode duration results in an estimate of the episode slip velocity, $V$.

\section{Results}

The results of the procedure described above are summarized in Table 1.

\subsection{Inferring Slow Slip Velocities}

Assuming no interepisode slip (no appreciable LFE occurrence between episodes), one implication of equation (2) is that at constant loading rate, $V_{L}$, perfectly periodic slip should result in the ratio of episode recurrence to episode duration being proportional to the normalized episode slip velocity

$$
t_{r}=t_{d}\left(V / V_{L}\right)
$$

Equation (3) has the advantage of having a clear time scale, $t_{r}$, over which the slip rate ratio $V / V_{L}$ is evaluated. Figure 5 shows the median values of episode duration and recurrence interval for the 88 families color coded by their MFD75. There are three populations made up of the short time scale episodic families (lower left group), short time scale continuous families (lower right group), and the long time scale episodic families (upper right). When the episodic families are evaluated on the long time scales, most episodes have days-long durations and tens-of-days long recurrence intervals (top right group) while continuous families typically have recurrence intervals of days and durations of minutes. When the episodic families are evaluated on short time scales, they have durations that are similar to the continuous families but recurrence intervals that are approximately an order of magnitude shorter. These bursts of events occur multiple times as part of longer duration creep events as shown in Figure 4c. The episodes of continuous families and episodic families with episodes defined using the short time scale show no trend in duration versus recurrence interval. The mean ratio of $t_{r}$ to $t_{d}$ for this group of families implies $V / V_{L}$ is of order $10^{2}$ and $10^{3}$. Assuming $V_{L}$ or a long-term deep slip rate 


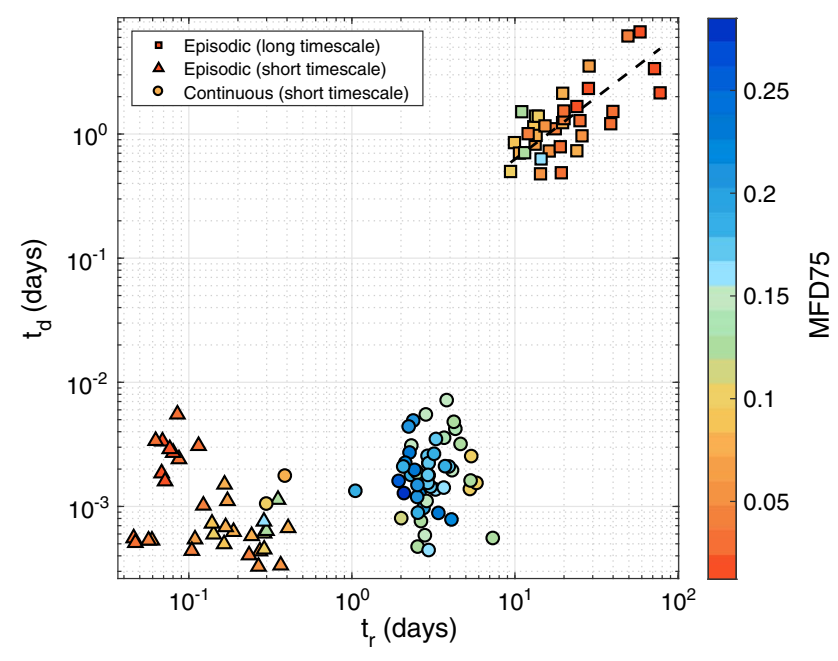

Figure 5. Median duration, $t_{d}$, versus recurrence interval $t_{r}$ of slip episodes in the 88 LFE families color coded by their MFD75 value (high values correspond to continuous families, while low values correspond to episodic families). The squares and triangles represent episodes defined by the long and short time scales (shown in Figure 4), while circles represent continuous families. Events separate into three populations. The continuous and short time scale episodic families show no systematic trend, while episodic families with episodes defined by the long $t_{r}$ time scale have $t_{d}$ that increases as a function of $t_{r}$. The dashed line is the best fit to this group of families and has a slope of 0.063 corresponding to $V / V_{L} \approx 16$. of $34 \mathrm{~mm} / \mathrm{yr}$ (Ryder \& Bürgmann, 2008), this result implies a slip rate of $10^{-7}$ to $10^{-6} \mathrm{~m} / \mathrm{s}$ during slip episodes for the continuous families. Finally, the longer duration episodes of the episodic families show a systematic relationship with duration increasing with recurrence interval. Superimposed on Figure 5 is a zero-intercept line of slope 0.063 , suggesting that the slip rate during episodes for episodic families is about 16 times the plate rate, or of order $10^{-8} \mathrm{~m} / \mathrm{s}$.

The slip estimates above are attractive in that they do not depend on an estimate of the slip per LFE $\left(d_{\mathrm{LFE}}\right)$. Figure 6 instead shows episode slip and slip rate determined using the average slip per LFE. Figure 6 suggests that while total slip increases as a function of episode duration, the slip rate in continuous and the short time scale episodic families is 2 orders of magnitude faster than the slip rate in the long time scale episodic families. Additionally, the specific slip velocities inferred using slip per LFE are largely consistent with those determined using equation (3).

\subsection{Interepisode Creep}

Equation (3) assumes that there is no slip between episodes. Whether this assumption is valid can be determined by using the fraction of intraepisode LFEs, $\chi$, described above, which is the ratio of the number of LFEs that occur during episodes to the total number. This definition assumes that events that do not take place within episodes are representative of the total amount of interepisode slip, $1-\chi \cdot \chi$ reaches its maximum value, one, if there is no interepisode slip. $\chi$ provides a context for defining and perhaps understanding the differences between the continuous and episodic families. Figure 7 shows that the continuous and short time scale episodic families have similarly short durations and $\chi$ values that vary substantially whereas episodic families have large $\chi$ values and relatively long durations. $\chi$ exceeds 0.9 for all the episodic families; hence, they are well coupled between episodes whereas $\chi$ values for the short time scale episodic and continuous families range between near 0.5 and 1 and as a whole are not consistent with equation (3). This variable fraction of interepisode LFEs may explain why the long time scale episodic families have a clear increase in duration with recurrence interval, as shown in Figure 5, and are generally consistent with equation (3), while the continuous and short time scale episodic families show no such trend.

Figures $8 \mathrm{a}$ and $8 \mathrm{~b}$ show the median slip per episode and median interepisode slip as a function of $\chi$ for the continuous, short and long time scale episodic families. Similar to Figure 5, long time scale episodic families with large $\chi$ values have much larger slip per episode (and longer durations). In the continuous and short time scale episodic families, the per episode slip is lower, independent of $\chi$, and does not overlap with the episodic families. In contrast, the average interepisode slip is similar for both episodic and continuous families (Figure 8)
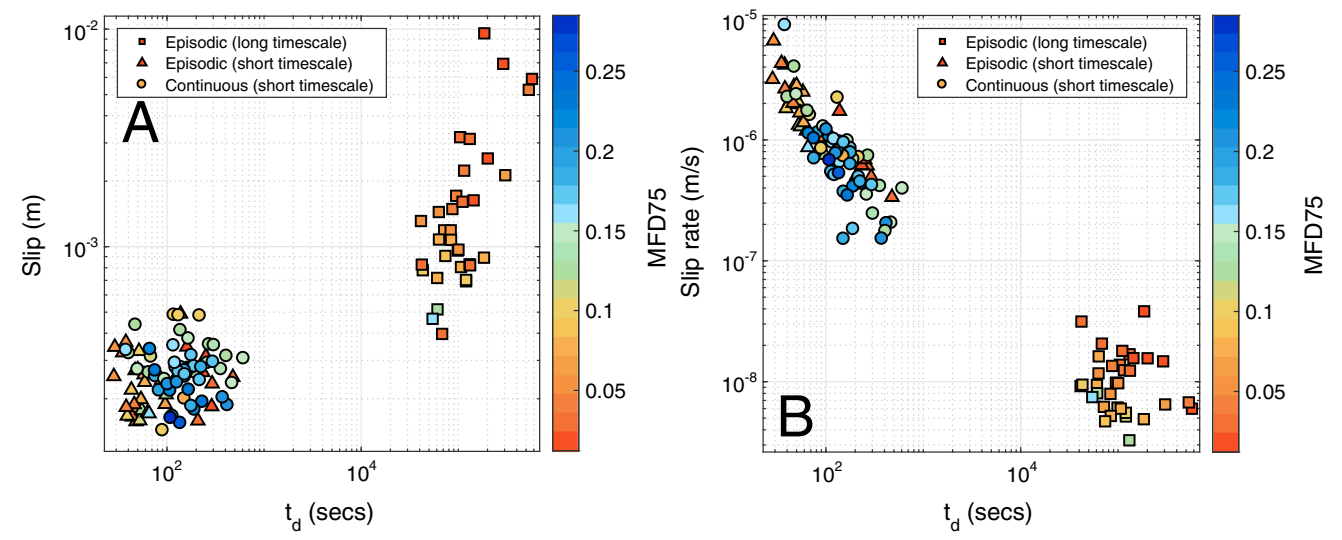

Figure 6. (a) The median duration, $t_{d}$, versus median slip per episode determined using the slip per LFE and LFEs per episode. (b) Median duration versus slip velocity measured over the duration of the episode. 


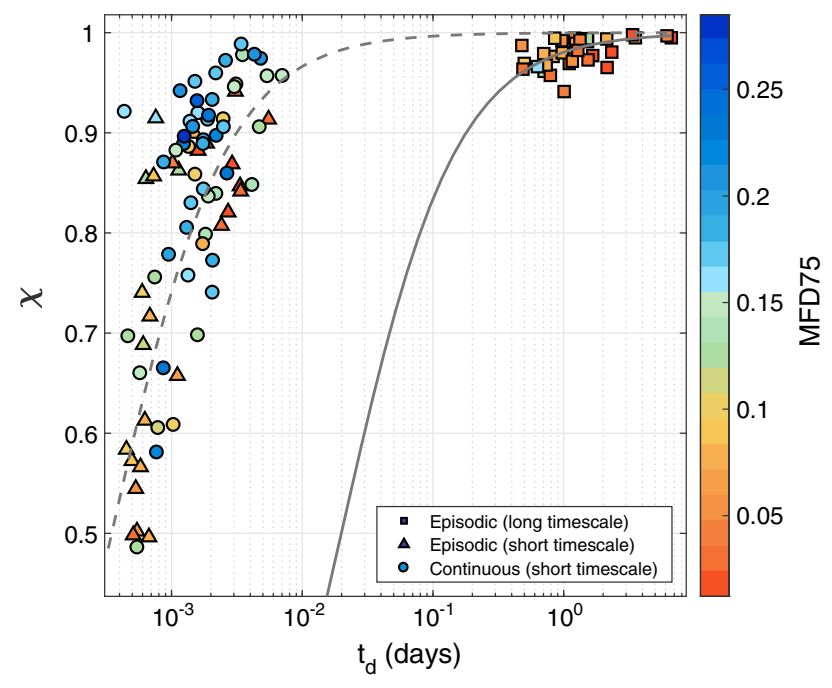

Figure 7. Median duration, $t_{d}$, versus $\chi$ of slip episodes in the 88 LFE families color coded by their MFD75 value. Once again LFE families separate into two populations. Episodic families generally have $\chi$ values near one and have long-duration episodes (around 1 day), whereas the continuous and short time scale families have strongly variable coupling that tends to increase as a function of episode duration. The dashed and solid lines are fits of equation (9) to all families and the episodic families alone.

despite the variability in $\chi$. The contrast in behavior, total slip, and duration suggests that the episodic and continuous families reflect mechanically different phenomena whereby the episodic families reflect periodic creep events, while continuous families may be driven by relatively continuous creep on surrounding fault. We further explore this idea in section 4.

\subsection{Moment-Duration Scaling of Inferred Creep Events}

Seismic moment is defined as

$$
M_{0}=\mu A d
$$

where $\mu$ is the rigidity, $A$ is the area of fault slip, and $d$ is the average slip. Ide et al. (2007) suggested that all slow earthquake phenomena (i.e., SSEs, NVT, and LFEs) obey linear moment-duration scaling. In contrast, traditional earthquakes have moment that scales with the cube of duration Kanamori and Anderson (1975). More recent studies have suggested that smallermoment SSEs may scale more like regular earthquakes because they are not geometrically confined (Gomberg et al., 2016). Because the creep episodes we identify are likely smaller than those constrained geodetically or from tremor zone dimensions in other environments, knowing their moment-duration scaling may inform the proposed scaling relationships. However, determining the moment of our inferred SSEs in Parkfield is challenging for a couple of reasons. First, while there is strong observational evidence for the occurrence of SSEs in Parkfield (Guilhem \& Nadeau, 2012; Shelly, 2015), these SSEs are too small for individual events to be detectable with surface geodetic monitoring equipment (Smith \& Gomberg, 2009). Delbridge (2015) showed that SSEs in Parkfield can be observed in strain meter records by stacking over multiple slip events; however, this does not allow for estimation of moments of individual SSEs. Second, knowing the slip alone does not allow for an estimate of the total moment; additional information is needed to estimate the area.

We estimate the relative difference in moment for these slip events in two different ways. We first assume constant rupture velocity, $V_{r}$, for all creep events identified using a given LFE family. Using this definition, the fault dimension $L=\sqrt{A}=t_{d} V_{r}$ and the relative moment is

$$
\frac{M_{o}}{M^{*}}=\frac{d_{e}}{d_{e}^{*}}\left(\frac{t_{d} V_{r}}{t_{d}^{*} V_{r}^{*}}\right)^{2},
$$

where the asterisks denote values for an arbitrarily chosen reference event. Alternatively, many slow earthquake phenomena are characterized by low stress drops of order $10 \mathrm{kPa}$ (Bartlow et al., 2014; Bletery et al., 2017; Bostock et al., 2015; Brodsky \& Mori, 2007; Hawthorne et al., 2016; Ide et al., 2007; Ito \& Obara, 2006;
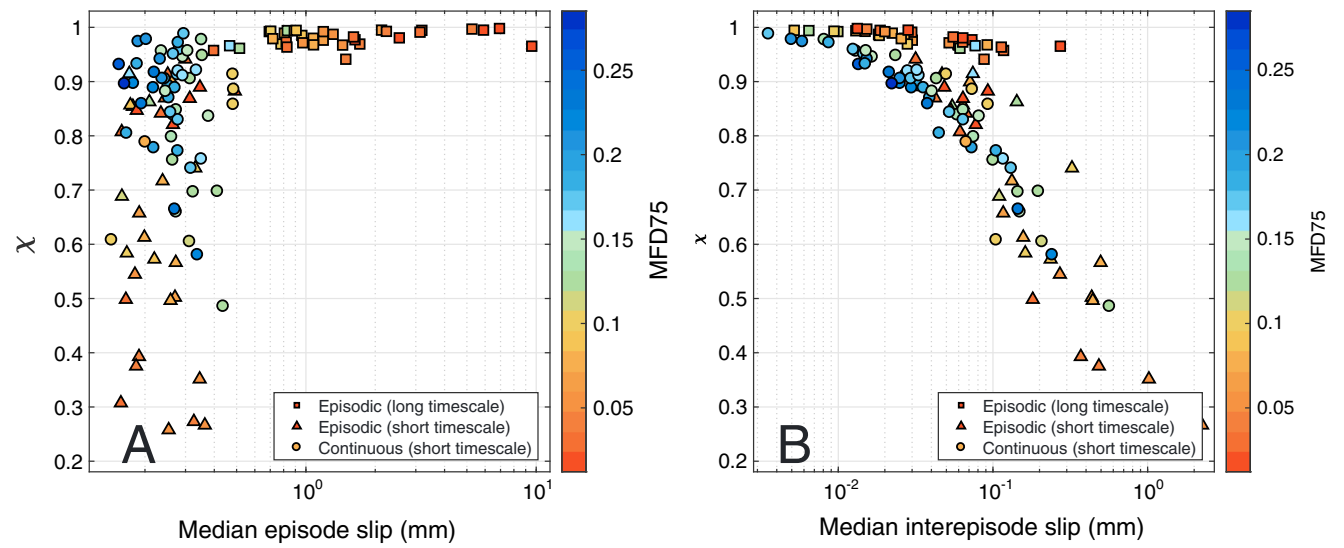

Figure 8. (a) $\chi$ versus median slip per episode. (b) $\chi$ versus median slip between episodes. 

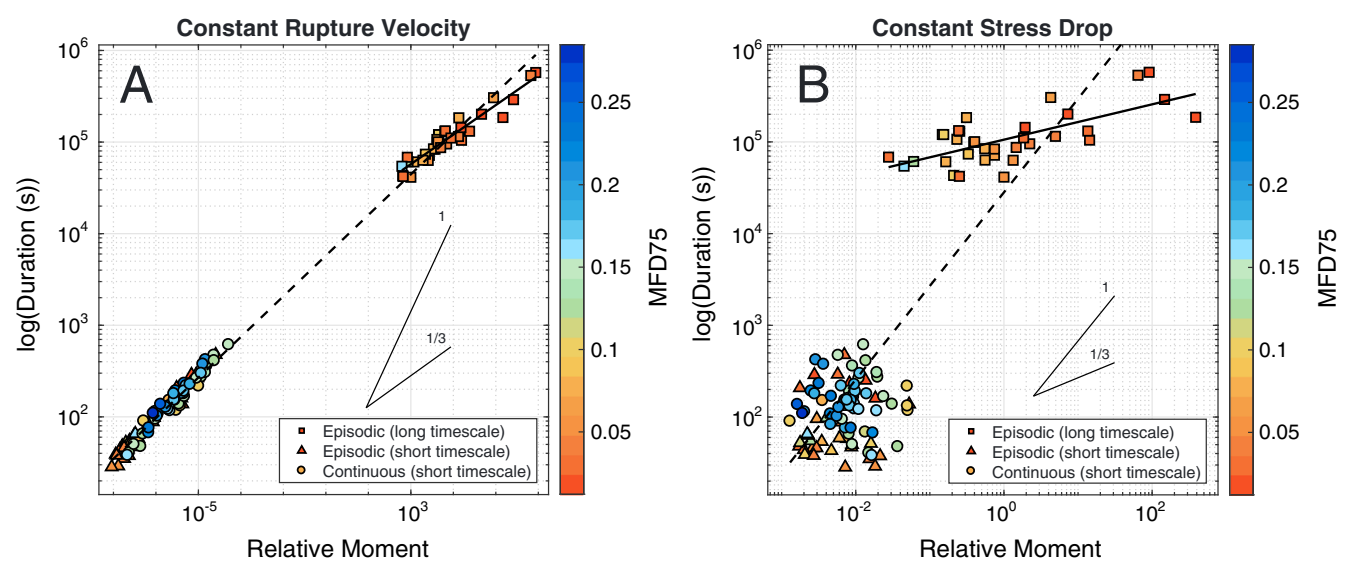

Figure 9. (a) The moment-duration scaling assuming constant rupture velocity (equation (5)). (b) The moment-duration scaling resulting from assuming constant stress drop (equation (7)). The best fit line to all families (dashed) in Figure 9a has a slope of 0.44 , close to the proposed 0.33 for regular earthquakes, while the fit to the moment-duration scaling shown in Figure $9 \mathrm{~b}$ has a slope of 1.02, close to linear moment-duration scaling proposed by lde et al. (2007). Fitting the episodic families only results moment-duration scaling of 0.32 and 0.19 for Figures $9 a$ and $9 b$, respectively. Solid lines show slopes of $1 / 3$ and 1 for reference.

Schmidt \& Gao, 2010; Thomas et al., 2016). The stress drop is defined as the difference in stress before and after a slip event and is proportional to the displacement divided by the dimension of the slipping region or

$$
\Delta \sigma=\alpha \mu \frac{d}{L}=\alpha \mu \frac{d}{\sqrt{A}} .
$$

If instead of taking $L=t_{d} V_{r}$ we assume that the Parkfield SSEs have similar stress drops and employ $L=\alpha \mu d / \Delta \sigma$ the relative moment is

$$
\frac{M_{o}}{M^{*}}=\left(\frac{d_{e}}{d_{e}^{*}}\right)^{3}
$$

Figures $9 \mathrm{a}$ and $9 \mathrm{~b}$ document the scaling that results from making these two assumptions. Figure $9 \mathrm{a}$ shows the moment-duration scaling assuming constant rupture velocity (equation (5), while Figure 9b shows the scaling resulting from assuming constant stress drop (equation (7)). The best fit line (dashed) in Figure 9a has a slope of 0.44 , close to the proposed 0.33 for regular earthquakes, while the fit to the moment-duration scaling shown in Figure $9 \mathrm{~b}$ has a slope of 1.02, close to linear moment-duration scaling proposed by lde et al. (2007).

\section{Discussion}

\subsection{Velocity Estimates for Creep Events}

SSEs around the world are observed to slip at speeds that are 1-2 orders of magnitude above the plate velocity. The near-constant slope of the episodic families evaluated on long time scales shown in Figure 5 suggests that equation (3) is valid and that these episodes represent creep events that slip $\approx 16$ times faster than the long-term slip rate. The data shown in Figures 5 and 6 suggest that the episodic families are a passive indicator of large-scale aseismic slip on the surrounding creep patches that fail periodically in SSEs and hence can be used as creepmeters on the time scale of $t_{r}$ (i.e., they are consistent with equation (3). The areas surrounding the LFE patches accommodate nearly $100 \%$ of their slip (as evidenced by large $\chi$ values in the long time scale episodic families) during few-day-long SSEs that recur several times each year and come to a halt in the inter-SSE period. Equation (3) is attractive in that in the absence of aseismic creep on the LFE patch, both the duration and the recurrence interval are properties of the Parkfield creep events that can be measured with confidence and hence the ratio of the slip velocity during creep events to the plate rate can be measured without relying on more speculative estimates of slip per LFE. Despite this uncertainty, the slip rates for the long-duration episodic families shown in Figure 6 are surprisingly consistent with those derived from equation (3) supporting the idea that these families do reflect surrounding creep.

The lack of a clear trend in $t_{r}$ versus $t_{d}$ in Figure 5 for the continuous and episodic families evaluated on short time scales suggests that equation (3) is not applicable. Since equation (3) employs estimates of both 
the duration, $t_{d}$, and recurrence interval, $t_{r}$, of inferred creep events, the lack of a clear $t_{r}$ versus $t_{d}$ trend suggests that either $t_{r}$ or $t_{d}$ is not representative. From Figure 6 the inference of lower slip rates during larger creep events is surprising in that the continuous families have shorter recurrence intervals, as in the presence of a constant stressing rate they should have less strain energy available to accelerate slip. Hence, these families should slip at lower average speeds than the less frequent episodic events. One way to have spurious slip velocities for these families is to have durations that are not meaningful; that is, they are not representative of the duration of surrounding creep episodes. Our preferred interpretation of these results is that continuous and short time scale episodic families likely are persistent asperities driven to failure by essentially continuous surrounding fault slip, similar to shallow repeating earthquakes, and do not reflect surrounding creep when evaluated over the time scale of a single recurrence interval. While this suggests, at least initially, that these families are not appropriate for use as a creepmeter, this result is a direct consequence of the time scale on which they are evaluated. When evaluated on time scales shorter than the burst recurrence time, $t_{r}$, there is no information on slip or slip rate and hence equation (3) is not applicable. Further support for this idea comes from the episodic families evaluated on short time scales shown in Figures 5 and 6 which, like the continuous families, show no trend in $t_{r}$ versus $t_{d}$ and have similar inferred slip rates. This suggests that for equation (3) to be applicable requires that they be evaluated on time scales that are longer than the fundamental interevent time. When evaluated on shorter time scales (as in the case of the short time scale episodic families), equation (3) yields unrealistic results.

Despite their inconsistency with equation (3), the continuous and short time scale episodic families are likely still useful creepmeters when their rates are evaluated on time scales much longer than a typical episode recurrence interval. To determine if this is true, we estimate the slip rate during the long time scale creep episodes by applying equation (2) to the short time scale episodic families over the median duration of a long time scale episode. Note that these two methods of estimating slip rate are independent, as the duration or recurrence interval of a long time scale episode need not correspond to the number of short time scale bursts it contains. If these families are useful creepmeters then we would expect the slip rates derived using equation (2) to be similar to those estimated by dividing the recurrence interval by the duration of the long time scale episodic families (i.e., equation (3) and Figure 5). We find that this is indeed the case, there is a very close correspondence between slip rates estimated using equations (2) and (3). While equation (3) yielded slip rate estimates of $V / V_{L} \approx 16$ for long time scale episodic families, equation (2) gives $V / V_{L} \approx 21$. Additionally, slip rates for the same family differ by $37 \%$ on average and by no more than a factor of 2.6 for any family. This result suggests that both continuous and short time scale episodic families can be used to monitor deep fault slip for transient increases that may precede large earthquakes; however, equation (2) must be evaluated over the appropriate time scale. For any recurring failure process, the assumption that time can be used as proxy for slip will break down at time scales shorter than the fundamental interevent time of the failure process. Because LFEs within a given family may not truly be repeating events (Bostock et al., 2015; Chestler \& Creager, 2017) and may not necessarily reflect surrounding fault slip, the interevent time scale is the time between bursts in the short time scale episodic families as opposed to the time between individual LFEs. The time scale between episodes in continuous families appears to have the same physical significance. Accordingly, if the 88 LFE families in Parkfield were to be used as deep creepmeters the time scale to evaluate equation (2) over would be several short time scale recurrence intervals (listed in Table 1).

There are a few additional observations that are worthy of discussion. First, while the continuous families generally have fewer LFEs per episode than episodic families (see Table 1), they still have multiple LFEs per episode (typically 3-8 LFEs). This could occur because the size of the persistent region is larger than an individual LFE asperity or because the slip accommodated when a continuous family experiences failure is larger than the maximum amount of slip any given LFE can accommodate (note that LFEs in Cascadia appear to have a maximum moment which they cannot exceed; see Bostock et al., 2015). Second, the continuous families have a larger fraction of interepisode LFEs than the episodic families many of which occur in isolation. These LFEs may be instances in which surrounding stress levels are too low to cause failure of the entire slip patch or in some cases they may represent false detections. Third, continuous and episodic families may be mechanically distinct; however, another possibility is that there simply are not regular slip transients in the locations of the continuous families. This idea is supported by the observations of Shelly (2017) that some families can switch between episodic and continuous deformation styles, suggesting that SSEs only sometimes reach their location. Fourth, if episodic families do meter creep that is approximately an order of magnitude faster than the long-term slip rate this provides a natural explanation for the recurrence intervals of the episodic families 
evaluated on short time scales being approximately an order of magnitude less than the continuous families as faster surrounding creep rates should produce correspondingly shorter recurrence intervals. Finally, previous studies have used analyses similar to that presented here to explore the spatial extent of interactions among families (Shelly, 2015; Trugman et al., 2015; Wu et al., 2015). In these studies, the continuous families do have occurrence patterns that are correlated over tens of kilometers which has been interpreted as long-range interaction among families (greater than $10 \mathrm{~km}$ in many cases). This observation appears to be inconsistent with our mechanical interpretation of the continuous families. Two possible explanations for this observation that still allow our hypothesis to hold are that LFEs in continuous families play an active role in propagating underlying creep fronts through a cascade-like failure process (as proposed by Shelly, 2015) or that the background driving stress, which includes contributions from long wavelength processes such as tectonics, tides, and hydrologic loads, pushes many families to failure nearly simultaneously manifesting as correlated failure of asperities separated by large distances.

\subsection{Creep Events and Interepisode Slip}

To better understand the observations in Figure 7, which shows $\chi$, the fraction of intraepisode LFEs, as a function of episode duration $t_{d}$, we consider the hybrid stick- and creep-slip model of repeating earthquakes developed by Beeler et al. (2001). The model considers a fault patch of dimension $L$ representing a region that undergoes episodic slip (i.e., earthquakes) and has material properties that are distinct from the fault patch surroundings. Slip on the surrounding fault drives slip on the patch; however, the patch is allowed to slip aseismically during the interseismic period as well as seismically while hosting repeating earthquakes. While Beeler et al. (2001) originally developed the model to study the moment-recurrence interval behavior of shallow repeating earthquakes on the SAF, slight modification of the initial assumptions allows for application to the deep creep events studied here. Throughout this manuscript we have assumed that slip is completely metered by LFE occurrence, meaning we assume that aseismic slip on the LFE asperity is negligible; hence, direct application of the Beeler et al. (2001) model is inappropriate. However, replacing seismic and aseismic slip in the case of repeating earthquakes with intraepisode and interepisode slip makes the model appropriate for application to deep creep events we study here. The modified model derivation is shown in Appendix A and results in a relationship between $\chi$, a strain hardening parameter, $C$, and the stiffness, $k$, of the fault patch hosting the creep event

$$
\chi=\frac{d_{e}}{d_{\text {total }}}=\frac{1}{1+k / C} .
$$

Equation (8) has a functional form that is consistent with the observations shown in Figure 7 provided that the ratio $k / C$ approaches one for the short-duration continuous families and goes to zero at durations associated with the long-duration episodic families. While equation (8) is expressed in terms of physical parameters in the model, a quick sanity check shows that it can be derived directly from the expression for the total slip budget (i.e., $d_{\text {ie }}+d_{e}=d_{\text {total }}$ ) as

$$
\chi=\frac{1}{1+\frac{d_{\mathrm{ie}}}{d_{e}}}=\frac{1}{1+\frac{d_{\mathrm{ie}}}{V_{e} t_{d}}} .
$$

Assuming $d_{\mathrm{ie}} / V_{e}$ is constant allows equation (9) to be fit directly to the observations shown in Figure 7. This fit is shown as a dashed line in Figure 7. We obtain a median value of $3.48 * 10^{-4}$ days for $d_{\text {ie }} / V_{e}$ and the fit captures some of the functional form of the observations. However, our calculated values of $d_{\mathrm{ie}} / V_{e}$ vary substantially with differences that exceed an order of magnitude between the episodic and continuous families. Additionally, as discussed in section 4.1, the velocity estimates for the continuous and short time scale episodic families are likely overestimated. Refitting equation (9) to the episodic families alone results in a value of $d_{\text {ie }} / V_{e}$ that is 0.020 days. This value is in good agreement with the median measured value of $d_{\mathrm{ie}} / V_{e}$ of 0.039 days for the episodic families.

An alternative interpretation of the data shown in Figure 7 can be gleaned from using the functional form in equation (8) but by employing the definition of stiffness, $k=G / L$, where $G$ is the rigidity of the surrounding rock and $L$ is the SSE patch length.

$$
\chi=\frac{1}{1+\frac{G}{L C}} .
$$




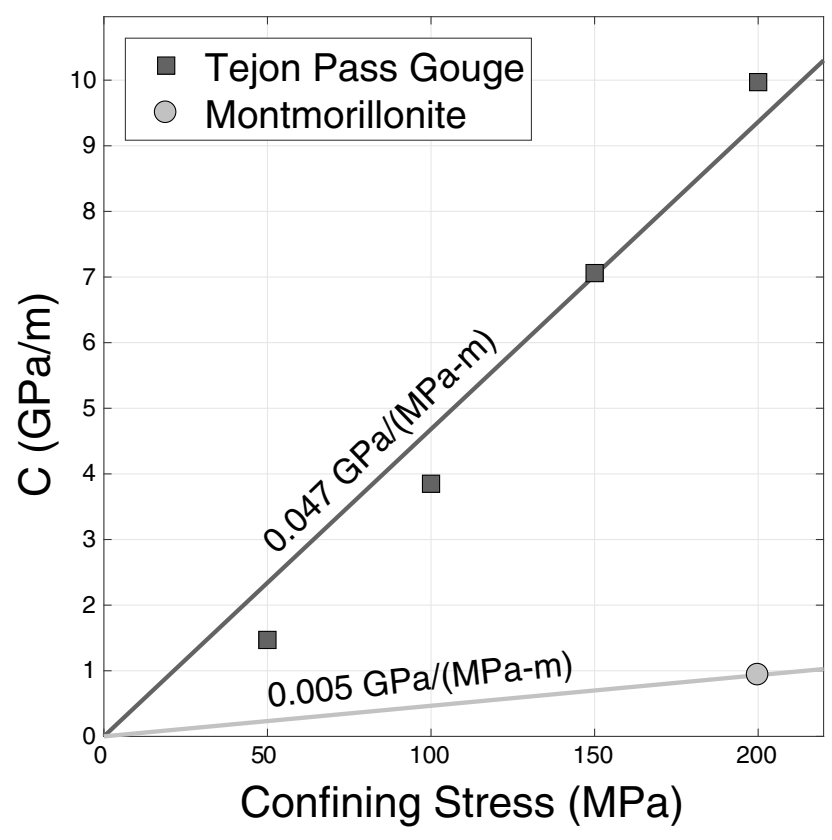

Figure 10. The strain hardening parameter $C$ of saturated Tejon Pass fault gouge measured at between 50 and $200 \mathrm{MPa}$ confining stress are shown as black squares, while $C$ for Montmorillonite is shown in gray from Morrow et al. (1982). C is the rate of strengthening with fault slip measured in $\mathrm{GPa} / \mathrm{m}$. The regressions (black and gray lines) are constrained to go through zero and gives the pressure dependence of $C$. Since $C$ is in $\mathrm{GPa} / \mathrm{m}$ and confining stress is in $\mathrm{MPa}$, the pressure dependence is measured in $\mathrm{GPa} /(\mathrm{MPa}-\mathrm{m})$.
In the context of this version of the Beeler et al. (2001) model, the variation in $\chi$ can be interpreted as being due to variations in the size of the slip events with families with smaller $\chi$ values having correspondingly smaller length scales and likely moments. The differences in inferred slip between long time scale episodic and continuous families further support this interpretation, as do numerical models of aseismic slip in repeating earthquakes (Chen \& Lapusta, 2009). Laboratory studies of strain hardening in saturated fault gouge suggest that the strain hardening parameter $C$ has an approximately linear pressure dependence (Morrow et al., 1982). Figure 10 shows measured values of $C$ as a function of confining stress from Morrow et al. (1982). These data were originally collected in a triaxial press on samples with a saw cut fault inclined at $30^{\circ}$ and have been converted from axial displacement to fault displacement for our purposes. Figure 10 shows that for the most extensively studied gouge from the Tejon Pass drilling project $C$ lies in the range of 2 to $10 \mathrm{GPa} / \mathrm{m}$ for confining stresses between 50 and $200 \mathrm{MPa}$, which correspond to lithostatic pressures at shallow to midcrustal depths (Morrow et al., 1982). There is only a single measurement for Montmorillonite, and it implies a much weaker pressure dependence of the strain hardening parameter of $0.005 \mathrm{GPa} / \mathrm{MPa}-\mathrm{m}$. The Tejon Pass gouge is the strongest and most strongly strain hardening material in Morrow et al. (1982) and has a pressure dependence of $0.047 \mathrm{GPa} / \mathrm{MPa}-\mathrm{m}$. Pore fluid pressures in the LFE source region on the deep San Andreas Fault are thought to be near lithostatic (Beeler et al., 2018, 2013; Thomas et al., 2012). Using an effective normal stress of $1 \mathrm{MPa}$ results in $C=0.047 \mathrm{GPa} / \mathrm{m}$. Using equation (10), $\chi=0.98$, the median $\chi$ value for the episodic families, and taking the shear modulus in the source region to be $30 \mathrm{GPa}$ results in a creep patch dimension of $\approx 30 \mathrm{~km}$, consistent with the estimates of Shelly (2015) and Trugman et al. (2015) deduced from the spatiotemporally coherent occurrence of the LFE families.

\subsection{Moment-Duration Scaling of Creep Events}

While it is fairly well accepted that large (i.e., M6 and above) SSEs are characterized by linear moment-duration scaling (Gao et al., 2012), whether smaller magnitude slow earthquakes or related phenomena (such as LFEs and VLFEs) have moment proportional to duration is unclear. Recently, Bostock et al. (2015) measured moments and durations of LFEs in Southern Vancouver Island and found that moment was proportional to duration to the tenth power reflecting the constant duration nature of LFEs. However, Bletery et al. (2017) estimate slip, area, and duration of secondary slip fronts in Cascadia, which are smaller-moment slip fronts that occur after the main slow slip front has passed, to show that such events obey linear moment-duration scaling, similar to large magnitude SSEs. Gomberg et al. (2016) suggested that large SSEs might follow the Scholz (1982) W model and obey linear moment-duration scaling because they fall in a region of bounded growth, in which the geometry of the slipping region can only grow in one dimension. Those authors used observations of creep events in Cascadia that had smaller spatial extents than the inferred transition zone width to argue that smaller-moment creep events have scaling consistent with unbounded growth (i.e., moment proportional to the cube of duration). Our inferred creep events may also have spatial extents that are equal to or less than the extent of the transition zone in Parkfield (Shelly, 2015); hence, estimates of moment and duration can inform the debate over how the moment of small magnitude creep events scale with duration.

Estimating the spatial extent of individual SSEs in Parkfield is challenging because individual SSEs are not geodetically detectable and LFE family locations are sparse (88 families spanning over $100 \mathrm{~km}$ along fault and $14 \mathrm{~km}$ in depth). As such, employing common (though not necessarily correct) assumptions, such as constant rupture velocity or constant stress drop, allows for estimates of relative SSE moments which may provide a useful constraint on the scaling. Because the frequent short-term bursts of the continuous families may not represent individual creep events, as proposed above, we consider only the moment duration trends of the episodic families alone. When we estimate relative moment assuming constant rupture velocity, the episodic families alone have a trend of 0.32 which is close to 0.33 , implying that creep events on the SAF have moment-duration scaling similar to regular earthquakes. Assuming a constant stress drop results in a scaling 


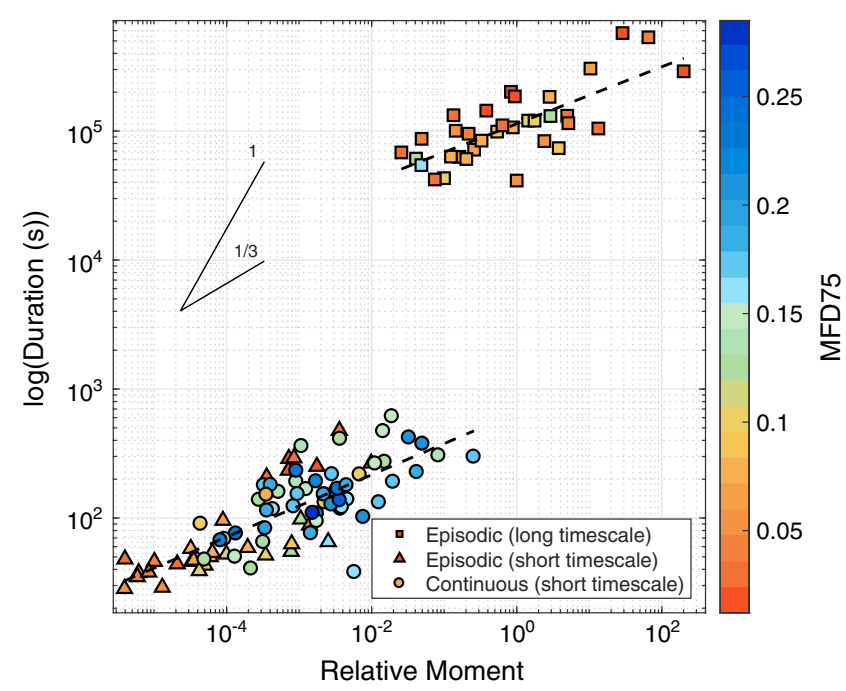

Figure 11. Moment-duration scaling determined using a length scaled derived from the model of Beeler et al. (2001). The slope for the continuous and short time scale episodic families is 0.24 . The slope for the episodic families is 0.22 . Solid lines show slopes of $1 / 3$ and 1 for reference. of 0.19 , inconsistent with either of the previously proposed scalings. Finally, the creep-slip model of Beeler et al. (2001) shown in equation (10) combined with laboratory estimates of the strain hardening parameter $C$ provide another means for estimating the length scale of creep events. We determine length scales of creep events by taking the $\chi$ values shown in Table 1, $C=0.047 \mathrm{GPa} / \mathrm{m}$ (assuming an effective stress of $1 \mathrm{MPa}$ ), and $\mu=30 \mathrm{GPa}$. Doing this results in the moment-duration scaling shown in Figure 11 that yields inferred scalings 0.22 episodic families and 0.24 for continuous and short time scale episodic families, respectively. One issue with using the Beeler et al. (2001) model to estimate spatial scale is that having $\chi$ values that approach one requires $K \ll C$. Very small stiffnesses can result in inferred length scales that are unrealistically large. For example, for the $C$ value we adopted the largest family, which has $\chi>0.99$ and has an inferred length scale of $\approx 300 \mathrm{~km}$. This problem could be alleviated by choosing a different value of $C$ for the episodic and continuous families. Thomas et al. (2012) found that more episodic families located at shallower depths are generally less correlated with small magnitude tidal shear stress fluctuations than deeper, more continuous families. They suggested that these variations in sensitivity to tidal stresses result from variations in effective stress and frictional properties. If such variations do reflect variations in pore fluid pressure then the episodic families may operate at larger effective stresses than the continuous families which justifies adopting different values of $C$ for the episodic and continuous families. Increasing $C$ by a factor of 5 for the episodic families (which corresponds to an effective stress of $5 \mathrm{MPa}$ ) results in maximum length scales on the order of tens of kilometers, which is consistent with the spatial extents inferred from other studies (Shelly, 2015; Trugman et al., 2015; Wu et al., 2015).

In summary, moments of SSEs in Parkfield are challenging to estimate due to the lack of knowledge of their spatial extents. The spatial extent of creep events in Parkfield are difficult to constrain reliably due to the sparseness of LFE locations. We instead determine relative moment, which can constrain the momentduration scaling of SSEs in Parkfield, by employing our measurements of slip and duration (see equations (5) and (7)). We estimate moment-duration scaling in three different ways: assuming constant rupture velocity, assuming constant stress drop, and employing the model of Beeler et al. (2001) to get spatial extents which we combine with our estimates of slip. None of these methods yields linear moment-duration scaling. While it is encouraging to find consistent results using different techniques to estimate the spatial extents of creep events in Parkfield, extreme caution should be exercised when attempting to determine scaling with incomplete knowledge of spatial scale.

\section{Conclusions}

Our analysis of creep events on the deep SAF yields the following results:

1. We find that the distribution of the logarithm of recurrence intervals of LFEs within a given family are either bimodal or trimodal. We call families with a bimodal distribution continuous while those with a trimodal distribution are episodic. We use the time scales between populations to identify episodes. In continuous families, the short and long recurrence interval populations represent LFEs that occur within episodes and LFEs that initiate episodes, respectively. Episodes in continuous families recur every few days. In the episodic families, the long recurrence interval populations are events that initiate episodes, the intermediate recurrence intervals are events that initiate bursts of events that occur within episodes, and the short recurrence intervals represent LFEs that occur within bursts of events. Episodic families recur on time scales of tens of days.

2. We formalized the definition of a creepmeter (i.e., equation (2) and determined its applicability to LFE families on the deep SAF). Because equation (2) has no inherent time scale, we recast it as equation (3) which suggests that the ratio of the recurrence interval to the duration can be used to estimate slip speeds during SSEs, which appear to be $\approx 16$ times the long-term plate slip rate in Parkfield. We find that continuous families and the short time scale episodic families are inconsistent with equation (3). However, when the short time scale episodic families are evaluated using (2) on time scales longer than the interevent time $t_{r}$ they can be used to determine meaningful slip rate estimates. Given the many similarities between 
the continuous and short time scale episodic families, this result likely extends to the continuous families as well.

3. A straightforward interpretation of episodic families is that they define sections of the fault where slip is distinctly episodic in well-defined SSEs. In contrast, the frequent short-term bursts of the continuous and short time scale episodic families likely do not represent individual creep events but rather are persistent asperities that are driven to failure by quasi-continuous slip on the surrounding fault.

4. A slightly modified version of the hybrid stick and creep-slip model of Beeler et al. (2001) provides a framework to interpret the observation that different families have variable coupling. The functional form of the model also suggests that the episodic families reflect episodic creep events with correspondingly larger moment, slip, duration, and, likely, scale.

5. We estimated moment-duration scaling of creep events assuming constant stress drop and constant rupture velocity and also estimated the spatial extent of the SSEs from the Beeler et al. (2001) model. All of the resulting moment-duration scalings are inconsistent with the proposed linear moment-duration scaling. However, caution must be exercised when attempting to determine scaling with incomplete knowledge of scale.

\section{Appendix A: Derivation of Hybrid Stick- and Creep-Slip Model for Deep Creep Events}

Beeler et al. (2001) derived a hybrid stick- and creep-slip model to study moment-recurrence interval relationships of shallow repeating earthquakes on the San Andreas Fault. Their model considers a fault patch of dimension $L$ representing a region that undergoes episodic slip and has material properties that are distinct from the fault patch surroundings. Slip on the surrounding fault drives slip on the patch. Stress on the patch is assumed to be uniform implying that it can be well characterized by a spatial average. To account for the total slip budget, the Beeler et al. (2001) model considers both seismic slip, $d_{\text {seis, }}$ that occurs during repeating earthquakes, and aseismic slip, $d_{\text {aseis }}$, that occurs between repeating earthquakes such that $d_{\text {seis }}+d_{\text {aseis }}=d_{\text {total }}$. To modify their original model, we replace $d_{\text {seis }}$ with the slip that occurs within episodes, $d_{e}$, and $d_{\text {aseis }}$ with the slip that occur between episodes, $d_{\mathrm{ie}}$, such that sum of the interepisode and intraepisode slip is the total slip, $d_{\mathrm{ie}}+d_{e}=d_{\mathrm{total}}$. Otherwise, the derivation follows that of Beeler et al. (2001). During the interseismic period the patch is loaded by elastic stress transfer from the surroundings and the shear stress on the patch, $\tau$, can be represented by

$$
\tau=k\left(d_{L}-d_{\mathrm{ie}}\right)=k\left(d_{0}+V_{L} t-d_{\mathrm{ie}}\right)
$$

where $t$ is time, and $d_{L}, d_{L 0}$, and $V_{L}$ are the displacement, the initial displacement, and the slip (or loading) velocity of the surroundings, respectively. Here $k$ is the stiffness $k=G / L$, where $G$ is the shear modulus, or equivalently the unloading stiffness, $k=\Delta \tau_{s} / d_{e}$, where $\Delta \tau_{s}$ is the static stress drop due to slip during an episode, $d_{e}$. The model considers a fault strength relation for the patch that allows for interseismic slip because in some families LFEs do not always occur as part of episodes, implying nonzero $d_{\mathrm{ie}}$. One relationship that satisfies this requirement is to allow patch strength prior to failure to be strain hardening, or an increasing function of the interepisode fault slip (e.g., Morrow et al., 1982). For simplicity we, like Beeler et al. (2001), assume this relationship is linear

$$
\tau_{\text {strength }}=\tau_{0}+C d_{\mathrm{ie}}
$$

where $C$ is a slip hardening coefficient and $\tau_{0}$ is the strength at the onset of loading. $C$ is intended to represent a ductile component to the region of interest and allows strain to accumulate without loss of strength. Because LFEs are thought to occur at the base of the crust, below the nominal depth of the brittle-ductile transition in California, it is appropriate to employ a model that allows for both brittle and ductile creep behaviors.

Equating (A1) with (A2) and noting that $\tau_{0}=k d_{0}$ results in an equation for the interseismic slip

$$
d_{\mathrm{ie}}=\frac{k V_{L} t}{C+k} \text {. }
$$

If the loading rate is constant, the slip rate of the patch is constant during the interepisode time:

$$
V_{\mathrm{ie}}=\frac{k V_{L}}{C+k} \text {. }
$$


When $\tau$ reaches a threshold strength $\tau_{f}$, a slip episode occurs and stress drops over some duration, $t_{d}$, to $\tau_{0}$. The static stress drop is then $\Delta \tau_{s}=\tau_{f}-\tau_{0}$. Combining this definition of stress drop with equation (A2) results in $\Delta \tau_{s}=C d_{\mathrm{ie}}$. Equation (A3) can be adapted to apply to a single interepisode time period by replacing the total interepisode slip $d_{\mathrm{ie}}$ with the interepisode slip of a single earthquake cycle $d_{\mathrm{ie}}$ and total time $t$ with the recurrence interval, $t_{r}$. Then the episode recurrence interval can be written as

$$
t_{r}=\frac{\Delta \tau_{s}}{V_{L}}\left(\frac{1}{k}+\frac{1}{C}\right)
$$

To determine the ratio of slip during an episode to the total slip, $\chi$, the "coupling" coefficient, we use the slip resulting from elastic unloading of the fault during an episode, given by $d_{e}=\Delta \tau_{s} / k$, and the total slip $d_{\text {total }}=V_{L} t_{r}$. Combining these definitions with equation (A5) leads to

$$
\chi=\frac{d_{e}}{d_{\text {total }}}=\frac{1}{1+k / C}
$$

\section{Acknowledgments}

All authors gratefully acknowledge support from the Southern California Earthquake Center award 72559471. A. M. T. and Q. B. acknowledge support from National Science Foundation award 1520238. We thank Aaron Wech, Jessica Hawthorne, Blandine Gardonio, and an anonymous reviewer for comments that greatly improved the manuscript. The LFE catalog used in this study can be found in the supporting information of Shelly (2017).

\section{References}

Bartlow, N. M., Wallace, L. M., Beavan, R. J., Bannister, S., \& Segall, P. (2014). Time-dependent modeling of slow slip events and associated seismicity and tremor at the Hikurangi subduction zone, New Zealand. Journal of Geophysical Research: Solid Earth, 119, 734-753. https://doi.org/10.1002/2013JB010609

Beeler, N., Lockner, D., \& Hickman, S. (2001). A simple stick-slip and creep-slip model for repeating earthquakes and its implication for microearthquakes at Parkfield. Bulletin of the Seismological Society of America, 91(6), 1797-1804.

Beeler, N. M., Thomas, A., Bürgmann, R., \& Shelly, D. (2018). Constraints on friction, dilatancy, diffusivity, and effective stress from low-frequency earthquake rates on the deep San Andreas Fault. Journal of Geophysical Research: Solid Earth, 123. https://doi.org/10.1002/2017JB015052

Beeler, N. M., Thomas, A., Bürgmann, R., \& Shelly, D. (2013). Inferring fault rheology from low-frequency earthquakes on the San Andreas. Journal of Geophysical Research: Solid Earth, 118, 5976-5990. https://doi.org/10.1002/2013JB010118

Bletery, Q., Thomas, A. M., Hawthorne, J. C., Skarbek, R. M., Rempel, A. W., \& Krogstad, R. D. (2017). Characteristics of secondary slip fronts associated with slow earthquakes in Cascadia. Earth and Planetary Science Letters, 463, 212-220.

Bostock, M., Thomas, A., Savard, G., Chuang, L., \& Rubin, A. (2015). Magnitudes and moment-duration scaling of low-frequency earthquakes beneath southern Vancouver island. Journal of Geophysical Research: Solid Earth, 120, 6329-6350. https://doi.org/10.1002/2015JB012195

Brodsky, E. E., \& Mori, J. (2007). Creep events slip less than ordinary earthquakes. Geophysical Research Letters, 34, L16309. https://doi.org/10.1029/2007GL030917

Bufe, C. G., Harsh, P. W., \& Burford, R. O. (1977). Steady-state seismic slip-A precise recurrence model. Geophysical Research Letters, 4(2), 91-94.

Chamberlain, C. J., Shelly, D. R., Townend, J., \& Stern, T. A. (2014). Low-frequency earthquakes reveal punctuated slow slip on the deep extent of the Alpine Fault, New Zealand. Geochemistry, Geophysics, Geosystems, 15, 2984-2999. https://doi.org/10.1002/2014GC005436

Chen, T., \& Lapusta, N. (2009). Scaling of small repeating earthquakes explained by interaction of seismic and aseismic slip in a rate and state fault model. Journal of Geophysical Research, 114, B01311. https://doi.org/10.1029/2008JB005749

Chestler, S., \& Creager, K. (2017). Evidence for a scale-limited low-frequency earthquake source process. Journal of Geophysical Research: Solid Earth, 122, 3099-3114. https://doi.org/10.1002/2016JB013717

Delbridge, B. (2015). Geodetic measurements of slow slip and tremor in Parkfield, CA. American Geophysical Union, Fall Meeting 2015, Abstract T43C-3014

Frank, W., Shapiro, N., Husker, A., Kostoglodov, V., Bhat, H., \& Campillo, M. (2015). Along-fault pore-pressure evolution during a slow-slip event in Guerrero, Mexico. Earth and Planetary Science Letters, 413, 135-143.

Gao, H., Schmidt, D. A., \& Weldon, R. J. (2012). Scaling relationships of source parameters for slow slip events. Bulletin of the Seismological Society of America, 102(1), 352-360.

Gomberg, J., Wech, A., Creager, K., Obara, K., \& Agnew, D. (2016). Reconsidering earthquake scaling. Geophysical Research Letters, 43, 6243-6251. https://doi.org/10.1002/2016GL069967

Guilhem, A., \& Nadeau, R. M. (2012). Episodic tremors and deep slow-slip events in Central California. Earth and Planetary Science Letters, $357,1-10$.

Hawthorne, J. C., Bostock, M. G., Royer, A. A., \& Thomas, A. M. (2016). Variations in slow slip moment rate associated with rapid tremor reversals in Cascadia. Geochemistry, Geophysics, Geosystems, 17, 4899-4919. https://doi.org/10.1002/2016GC006489

Houston, H., Delbridge, B. G., Wech, A. G., \& Creager, K. C. (2011). Rapid tremor reversals in Cascadia generated by a weakened plate interface. Nature Geoscience, 4, 404-409. https://doi.org/10.1038/ngeo1157

Ide, S., Beroza, G. C., Shelly, D. R., \& Uchide, T. (2007). A scaling law for slow earthquakes. Nature, 447, 76-79. https://doi.org/10.1038/nature05780

Ito, Y., \& Obara, K. (2006). Very low frequency earthquakes within accretionary prisms are very low stress-drop earthquakes. Geophysical Research Letters, 33, L09302. https://doi.org/10.1029/2006GL025883

Kanamori, H., \& Anderson, D. L. (1975). Theoretical basis of some empirical relations in seismology. Bulletin of the Seismological Society of America, 65(5), 1073-1095.

Kato, A., \& Nakagawa, S. (2014). Multiple slow-slip events during a foreshock sequence of the 2014 lquique, Chile $M_{w} 8.1$ earthquake. Geophysical Research Letters, 41, 5420-5427. https://doi.org/10.1002/2014GL061138

Kato, A., Obara, K., Igarashi, T., Tsuruoka, H., Nakagawa, S., \& Hirata, N. (2012). Propagation of slow slip leading up to the $2011 M_{w} 9.0$ Tohoku-Oki earthquake. Science, 335(6069), 705-708.

Mavrommatis, A. P., Segall, P., Uchida, N., \& Johnson, K. M. (2015). Long-term acceleration of aseismic slip preceding the $M_{W} 9$ Tohoku-Oki earthquake: Constraints from repeating earthquakes. Geophysical Research Letters, 42, 9717-9725. https://doi.org/10.1002/2015GL066069 
Meng, L., Huang, H., Bürgmann, R., Ampuero, J. P., \& Strader, A. (2015). Dual megathrust slip behaviors of the 2014 lquique earthquake sequence. Earth and Planetary Science Letters, 411, 177-187.

Morrow, C., Shi, L., \& Byerlee, J. (1982). Strain hardening and strength of clay-rich fault gouges. Journal of Geophysical Research, 87(B8), $6771-6780$.

Nadeau, R., \& McEvilly, T. (1999). Fault slip rates at depth from recurrence intervals of repeating microearthquakes. Science, 285(5428), $718-721$.

Obara, K. (2002). Nonvolcanic deep tremor associated with subduction in southwest Japan. Science, 296, 1679-1681. https://doi.org/10.1126/science.1070378

Obara, K. (2010). Phenomenology of deep slow earthquake family in southwest Japan: Spatiotemporal characteristics and segmentation. Journal of Geophysical Research, 115, B00A25. https://doi.org/10.1029/2008JB006048

Obara, K., Matsuzawa, T., Tanaka, S., \& Maeda, T. (2012). Depth-dependent mode of tremor migration beneath Kii Peninsula, Nankai subduction zone. Geophysical Research Letters, 39, L10308. https://doi.org/10.1029/2012GL051420

Royer, A. A., Thomas, A. M., \& Bostock, M. G. (2015). Tidal modulation and triggering of low-frequency earthquakes in northern Cascadia. Journal of Geophysical Research: Solid Earth, 120, 384-405. https://doi.org/10.1002/2014JB011430

Ruiz, S., Metois, M., Fuenzalida, A., Ruiz, J., Leyton, F., Grandin, R., ... Campos, J. (2014). Intense foreshocks and a slow slip event preceded the 2014 lquique $M_{W} 8.1$ earthquake. Science, 345(6201), 1165-1169.

Ryder, l., \& Bürgmann, R. (2008). Spatial variations in slip deficit on the central San Andreas Fault from InSAR. Geophysical Journal International, 175, 837-852. https://doi.org/10.1111/j.1365-246X.2008.03938.x

Schaff, D. P., Beroza, G. C., \& Shaw, B. E. (1998). Postseismic response of repeating aftershocks. Geophysical Research Letters, 25(24), $4549-4552$.

Schmidt, D. A., \& Gao, H. (2010). Source parameters and time-dependent slip distributions of slow slip events on the Cascadia subduction zone from 1998 to 2008. Journal of Geophysical Research, 115, B00A18. https://doi.org/10.1029/2008JB006045

Scholz, C. H. (1982). Scaling laws for large earthquakes: Consequences for physical models. Bulletin of the Seismological Society of America, 72(1), $1-14$.

Shelly, D. R. (2009). Possible deep fault slip preceding the 2004 Parkfield earthquake, inferred from detailed observations of tectonic tremor. Geophysical Research Letters, 36, L17318. https://doi.org/10.1029/2009GL039589

Shelly, D. R. (2015). Complexity of the deep San Andreas Fault zone defined by cascading tremor. Nature Geoscience, 8(2), $145-151$.

Shelly, D. R. (2017). A 15-year catalog of more than 1 million low-frequency earthquakes: Tracking tremor and slip along the deep San Andreas Fault. Journal of Geophysical Research: Solid Earth, 122, 3739-3753. https://doi.org/10.1002/2017JB014047

Shelly, D. R., \& Johnson, K. M. (2011). Tremor reveals stress shadowing, deep postseismic creep, and depth-dependent slip recurrence on the lower-crustal San Andreas Fault near Parkfield. Geophysical Research Letters, 381, L13312. https://doi.org/10.1029/2011GL047863

Shelly, D. R., Beroza, G. C., \& Ide, S. (2007). Non-volcanic tremor and low-frequency earthquake swarms. Nature, 446, 305-307. https://doi.org/10.1038/nature05666

Sieh, K. E. (1978). Prehistoric large earthquakes produced by slip on the San Andreas Fault at Pallett Creek, California. Journal of Geophysical Research, 83(B8), 3907-3939.

Smith, E. F., \& Gomberg, J. (2009). A search in strainmeter data for slow slip associated with triggered and ambient tremor near Parkfield, California. Journal of Geophysical Research, 114, B00A14. https://doi.org/10.1029/2008JB006040

Thomas, A. M., Bürgmann, R., Shelly, D. R., Beeler, N. M., \& Rudolph, M. L. (2012). Tidal triggering of low frequency earthquakes near Parkfield, California: Implications for fault mechanics within the brittle-ductile transition. Journal of Geophysical Research, 117, B05301. https://doi.org/10.1029/2011JB009036

Thomas, A. M., Beroza, G. C., \& Shelly, D. R. (2016). Constraints on the source parameters of low-frequency earthquakes on the San Andreas Fault. Geophysical Research Letters, 43, 1464-1471. https://doi.org/10.1002/2015GL067173

Trugman, D. T., Wu, C., Guyer, R. A., \& Johnson, P. A. (2015). Synchronous low frequency earthquakes and implications for deep San Andreas Fault slip. Earth and Planetary Science Letters, 424, 132-139.

Uchida, N., linuma, T., Nadeau, R. M., Bürgmann, R., \& Hino, R. (2016). Periodic slow slip triggers megathrust zone earthquakes in northeastern Japan. Science, 351(6272), 488-492.

Wech, A. G., \& Creager, K. C. (2011). A continuum of stress, strength and slip in the Cascadia subduction zone. Nature Geoscience, 4, 624-628. https://doi.org/10.1038/ngeo1215

Wu, C., Guyer, R., Shelly, D., Trugman, D., Frank, W., Gomberg, J., \& Johnson, P. (2015). Spatial-temporal variation of low-frequency earthquake bursts near Parkfield, California. Geophysical Journal International, 202(2), 914-919. 